\title{
Las conexiones ocultas
}

\section{Germán Bula*}

Resumen: La educación consiste en hacer ver al educando que está constituido por, y es parte de, múltiples sistemas y subsistemas de índole social, ambiental y cósmico. Esta educación representa un desarrollo al mismo tiempo cognitivo, ético, emotivo y espiritual. Esta visión de la educación se opone a diversas formas de reduccionismo que no dejan ver las conexiones importantes entre los fenómenos y entre éstos y el observador. En términos éticos, este aprendizaje consiste en el reconocimiento y la producción de juegos de suma positiva. Espiritualmente, consiste en un sentimiento de vínculo con la totalidad, que produce asombro, gratitud y respeto ante el milagro de la existencia.

Palabras clave: holismo, educación, ética, Spinoza, Bateson

\section{The hidden connections}

Abstract: Education consists in making students perceive that they are constituted by, and part of, multiple social, environmental and cosmic systems and subsystems. This education entails a development that is at the same time cognitive, ethical, emotive and spiritual. This vision of education is opposed to several forms of reductionism that obscure important connections between phenomena and between these and the observer. In ethical terms, this learning consists in the recognition and production of positive sum games. Spiritually, it consists of a feeling of togetherness with totality, which produces amazement, gratitude and respect towards the miracle of existence.

Key words: holism, education, ethics, Spinoza, Bateson

\section{As conexões ocultas}

Resumo: A educação consiste em fazer ver ao educando que está constituído por e é parte de múltiplos sistemas e subsistemas de índole social, ambiental e cósmica. Esta educação representa um desenvolvimento ao mesmo tempo cognitivo, ético, emotivo e espiritual. Esta visão da educação opõe-se a diversas formas de reduccionismo que não deixam ver as conexões importantes entre os fenómenos e entre estes e o observador. Em termos éticos, esta aprendizagem consiste no reconhecimento e a produção de jogos de soma positiva. Espiritualmente, consiste num sentimento de vínculo com a totalidade, que produz assombro, gratidão e respeito ante o milagre da existência.

Palavras-chave: holismo, educação, ética, Spinoza, Bateson

Recibido: 11.11.2009

Aceptado: 07.02.2010

$* * *$

*Universidad de la Salle, Bogotá, Colombia. Email: gbulalo@unisalle.edu.co 
Cuando vinieron los nazis por los comunistas, guardé silencio, pues yo no era comunista

Cuando encarcelaron a los socialdemócratas, guardé silencio, pues yo no era socialdemócrata

Cuando vinieron a buscar a los sindicalistas, no protesté, pues yo no era sindicalista Cuando vinieron a buscar a los judíos, no protesté, pues yo no era judío Cuando vinieron a arrestarme no quedaba nadie que pudiera protestar ${ }^{1}$

(Martin Niemöller) $^{2}$

La educación, nos dice Vaclav Havel (2000) es la percepción de las conexiones ocultas entre los fenómenos. Esta frase tiene diversas lecturas posibles, triviales o profundas. Quien es educado en los puntos de ebullición percibe una conexión entre la temperatura y el agua hirviendo que antes no percibía, pero esto es una verdad de Perogrullo. En este ensayo defenderemos que, en un sentido importante, la educación, la educación que es capaz de transformar a los individuos, las sociedades y el mundo, es la percepción de las conexiones ocultas entre los fenómenos.

El tema del poema de Martin Niemöller que hemos citado como epígrafe no parece ser la epistemología, al menos a primera vista. El poema es una denuncia del pastor protestante al egoísmo y la indiferencia de la sociedad alemana (y suya propia) durante el régimen nazi. Sin embargo; si Niemöller no hubiese clasificado a las víctimas de los nazis como comunistas, socialdemócratas, sindicalistas y judíos sino como alemanes, hubiera intervenido antes de que fuera demasiado tarde, según la lógica interna del poema. Dicho de otro modo, si Niemöller hubiera percibido los vínculos que le unían a las otras víctimas de los nazis, si se hubiera concebido a sí mismo y a los judíos como parte de un mismo cuerpo social, hubiera actuado de manera diferente. Si la tesis que aquí defenderemos es cierta, el egoísmo y la indiferencia no son sólo falencias morales, sino también cognitivas, y la educación tiene la posibilidad de cambiarlas.

La educación puede tener un papel transformador siempre y cuando esté consciente de ciertas conexiones importantes entre los fenómenos. Tra-

\footnotetext{
${ }^{1}$ La versión original alemana dice así: Als die Nazis die Kommunisten holten/habe ich geschwiegen;/ich war ja kein Kommunist./Als sie die Sozialdemokraten einsperrten,/habe ich geschwiegen;/ich war ja kein Sozialdemokrat./Als sie die Gewerkschafter holten,/habe ich nicht protestiert;/ich war ja kein Gewerkschafter./Als sie die Juden holten,/habe ich nicht protestiert;/ ich war ja kein Jude./Als sie mich holten,/gab es keinen mehr, /der protestieren konnte.

${ }^{2}$ Ha sido atribuída erróneamente a Bertold Brecht.
} 
dicionalmente, por ejemplo, la educación asume que las conexiones están ocultas para el alumno, y son patentes para el educador. Es decir, no concibe a educadores y educandos como parte de una comunidad de investigadores. Otra falla de la concepción tradicional de la educación tiene que ver con el olvido de las conexiones entre disciplinas; los seres humanos abstraemos ciertos tipos de fenómenos y los volvemos objeto de disciplinas especializadas (la física, la química, la sociología, etc.), pero el mundo a partir del cual hacemos estas abstracciones es uno solo; y a menudo olvidamos que nuestros mapas no son el territorio, y caemos en el reduccionismo. Finalmente, un excesivo celo por la objetividad hace que la educación tradicional olvide las conexiones que hay entre el objeto de estudio y aquel que lo estudia. El error que conlleva olvidar esta última conexión ya lo hemos señalado en nuestra discusión del poema de Niemöller, quien observaba de manera objetiva y objetivante los abusos contra comunistas y judíos, sin percatarse de lo que estos fenómenos tenían que ver con él mismo.

Estas conexiones se conectan entre sí a su vez. Cuando el "a-lumno” (aquel que no tiene luz) es concebido como un mero receptáculo de un saber preexistente, no se le está concibiendo como un ser humano total, sino de forma reduccionista. Este trato objetivante hacia el estudiante está causalmente unido a un trato objetivante frente a los temas de estudio: no son Ana o Pablo quienes estudian la historia de Colombia, sino un par de máquinas de Turing recibiendo unos símbolos por los ojos y los oídos y produciendo otros con sus manos y su boca. Ahora bien, las máquinas de Turing no se apasionan con nada, ni se hacen responsables de nada; sólo producen símbolos a partir de otros símbolos usando leyes sintácticas ajustadas a la semántica de los mismos.

¿Qué es el reduccionismo? No puede definirse como el presentar o concebir los fenómenos con una complejidad menor a la que en realidad tienen. Esta clase de reduccionismo es, de hecho, inevitable: el mundo es infinitamente complejo y nuestros libros, mentes y discursos son finitos. En todos nuestros mapas (cartográficos, científicos, populares, filosóficos), reducimos la complejidad del territorio que representamos; un buen mapa se olvida de los rasgos irrelevantes del territorio y resalta los relevantes (el mapa vial de Bogotá no indica la densidad de población en cada zona, por ejemplo). El reduccionismo se da, más bien, cuando nuestros mapas olvidan rasgos importantes del territorio (Beer, 1993); cuando al tratar con seres humanos los vemos como algo menos que seres humanos, o cuando olvidamos, como Niemöller, cómo estamos nosotros mismos conectados con el resto del mundo. Está bien que las ciencias económicas abstraigan ciertos rasgos del mundo y de los seres humanos para simplificar y hacer posibles sus cálculos, está bien que supongan en esto que "todo lo demás permanece igual” (ceteris paribus); pero es científica y moralmente errado abstraer el impacto ambiental de los cálculos económicos, barrer debajo de la cama el dióxido de carbono y los metales pesados con el rótulo de “externalidades”, de factores irrelevantes para el cálculo económico. Esto es reduccionismo. 
El objeto de la biología (en cuanto trata el cuerpo humano), de la neurociencia, de la psicología, de la epistemología y de las ciencias sociales, es el mismo: el ser humano. Si bien abstraemos aspectos de este único objeto para estudiarlos bajo disciplinas diferentes, los seres humanos no somos mente por una parte, cuerpo por otra, sentimientos por otra y seres sociales por otra; somos todo esto a la vez y de manera integrada.

El modelo del hombre que tiene la filosofía de Spinoza resulta útil para pensarnos a nosotros mismos de manera holista. Cuerpo y mente son, para Spinoza, manifestaciones diferentes y paralelas de una única actividad subyacente, de un conatus (Misrahi, 1998); de manera análoga a como una partitura y un registro de ondas sonoras pueden registrar el mismo sonido. Asimismo, la actividad mental del hombre no está parcelada en facultades, ni se parece al alma tripartita platónica, sino que todo evento cognitivo es al mismo tiempo un evento emocional y un evento conativo (Ravven 1989), como ciertos desarrollos recientes en la neurociencia parecen confirmar (Ravven, 2003, Damasio 2003). Dicho de otro modo, lo cognitivo, conativo y emocional son sencillamente tres maneras de describir una misma actividad autoafirmante.

Podemos ilustrar esta idea volviendo al poema de Niemöller. Éste se lamenta de una determinada actitud (conativa) respecto a los abusos de los nazis. Ahora bien, ya hemos mostrado que esta actitud es el correlato de una cierta manera de ver el mundo a nivel cognitivo, un olvido de las conexiones entre el sujeto y el objeto de observación. Este olvido de las conexiones entre sujeto y objeto tiene, además, un correlato emocional: la indiferencia. Así pues, el error de Niemöller es a la vez cognitivo, conativo y emocional; o más bien, contamos como observadores con estas tres maneras de describir su error. Martin Niemöller, como proceso dinámico involucrado con el mundo, no amplio su rango de acción lo suficiente, no supo acoplarse a un entorno cambiante: no obró, no conoció, no deseó.

El concepto de gestalt como lo plantea Arne Naess (2001), y el concepto umwelt, de Jakob von Uexkull, proporcionan una perspectiva integradora de los tres aspectos de la actividad humana; cognitiva, conativa y emotiva. El umwelt de un organismo es su entorno efectivo, esto es, el entorno que, en cuanto ser viviente, el organismo produce. En efecto, parte de la actividad, de la lucha por la vida, de un organismo consiste en percibir, organizar, darle sentido a los estímulos externos, seleccionando y destacando aquello que es útil a la acción.

El umwelt incluye percepciones sensoriales pero también lo que el organismo resalta como peligro u oportunidad, así como la dimensión de sentido de lo percibido y los sentimientos que esto suscita (Kull, 1998). Dicho de otro modo, el umwelt es el mundo en el que efectivamente habita el organismo, el mundo visto, deseado, planificado y sentido por un organismo particular.

Mientras que el concepto de gestalt de Naess enfatiza el carácter 
holista de los diferentes mundos en que habitamos, el concepto de umwelt enfatiza el sustrato biológico de nuestro entorno efectivo (que tiene que ver con la particular constitución de nuestro cuerpo, así como el umwelt de una abeja tiene que ver con el suyo); el hecho de que el umwelt no es la aprehensión del mundo por parte de un agente pasivo sino de un organismo, de un proceso vital. Sirva el siguiente ejemplo para explicar ambos conceptos:

Una niña de dos años mira, sentada en la cama, como su padre empaca con afán una maleta. El padre, a punto de terminar y con poco espacio de sobra en la maleta, toma el oso de peluche de la niña y lo embute entre las camisetas y un par de zapatos, de modo que la cabeza del oso se dobla hasta tocar sus piernas. En el mundo de la niña, se acaba de cometer una agresión; el oso sufrirá durante todo el viaje por su incómoda posición. Para el padre, lo único que ha sucedido es que la tarea de empacar se ha concluido. La diferencia es una de ontología; padre y niña viven en mundos diferentes, productos de historias diferentes de relaciones con el entorno. Tan "subjetiva" es la visión del padre como la de la niña, en ambos casos se trata de una aprehensión gestáltica de la situación producto de una red de relaciones determinada entre las personas y su entorno. A menudo, los debates éticos son debates ontológicos, especialmente en lo relativo al medioambiente: en diversos gestalts un bosque puede aparecer como un espacio sin aprovechar, un ser con vida respecto al que se tienen emociones, una cantidad de toneladas de madera utilizable, etc. La confrontación ocurre porque los diversos bandos viven en mundos diferentes (Bula, 2009, 11)

La educación, en la medida en que es efectiva, produce un cambio en el umwelt o gestalt del educando. Supongamos un curso de sensibilización contra el racismo en un colegio multirracial a través de relatos en los que se ve el sufrimiento de las minorías víctimas de racismo; tal curso sólo será efectivo en la medida en que los miembros de la minoría racial se conviertan, en el umwelt de los alumnos del colegio, en seres vulnerables y dignos de respeto. Si el aprendizaje no pasa de la mera repetición verbal, si no queda incorporado en el entorno efectivo de los alumnos, no ha sucedido nada.

Una transformación en el umwelt equivale a una transformación ética. En el umwelt de un envidioso, los bienes ajenos aparecen como bienesno-disfrutados-por-mi; en el de un paranoico los planes e intenciones de las demás personas aparecen como amenazas. En el umwelt que quisiera para mi hija, las oportunidades de ayudar a otros aparecen como ocasiones de gratitud. Un umwelt que coincide con una buena formación ética es uno en el que tienen relieve las conexiones de interdependencia entre el individuo y su entorno social, natural, familiar, político, etc.

¿En qué consiste, pues, el desarrollo ético-emotivo-cognitivo que puede proporcionar la educación? El mundo es una enorme y densa red de 
conexiones causales entre los fenómenos; a través de la educación, se debe producir una red de conexiones entre conceptos que se haga cada vez más amplia y más densa, reflejando la red de conexiones entre los fenómenos (Capra, 1996).

¿Cómo se logra que el conocimiento tenga un impacto a nivel conativo y emocional, que no se quede en la mera teoría sino que transforme al individuo completo? Incluyendo al educando mismo en la red de conceptos (por supuesto, está incluido en la red de relaciones causales entre fenómenos). Esto equivale a indicar al educando la manera en que los demás fenómenos del mundo le impactan y le implican. Sin necesidad de sentimentalismos amarillistas, esta conexión proporciona a la educación la fuerza conativa y emotiva necesaria. El desarrollo, ayudado por la educación, tendrá el aspecto de una red de conceptos, de responsabilidades y de lugares de interés emocional que se hace progresivamente más amplia y más densa. En efecto, las redes en que existimos son redes de interdependencia, los sistemas a los que pertenecemos nos configuran y sostienen; aprender de estos sistemas y de nuestro lugar en ellos es aprender a cuidar de ellos, y participar de su grandeza.

Los adolescentes suelen creer que existen de manera independiente, sin relación con su familia, su comunidad o su historia. Madurar consiste en darse cuenta que uno está sostenido por vínculos amorosos, y que el bienestar de la familia a la que se pertenece tiene que ver con el bienestar propio. Y consiste también en darse cuenta de que uno es sostenido por una comunidad, y que uno debe, por lo tanto, contribuir a esta comunidad, esto es, trabajar para dicha comunidad.

¿Hemos pasado de premisas cognitivas a conclusiones prescriptivas, brincado del es al debe, hemos cometido la falacia naturalista? El conocimiento, tal como lo describimos, lleva a la responsabilidad de manera causal, psicológica; no sirve como premisa para concluir de ella obligaciones, la obligación no se deriva de manera lógica. No media entre el conocimiento y la acción una premisa prescriptiva: si me lastimo mi mano, me apresuro a sanarla porque es parte de mí, sin necesidad de imperativo categórico alguno. Si comprendo que mi esposa y yo somos parte de un todo superior, la cuido con la misma espontaneidad con la que cuido mi mano: se me aparecerá, en mi umwelt, como algo que debe ser cuidado. Si Niemöller hubiera comprendido que él y los judíos y comunistas hacían parte de un todo más amplio, del que su salud individual dependía, ayudarlos hubiera parecido el curso de acción normal. Hacerse responsable es comprender las redes de relaciones de las que dependo y que me constituyen.

¿Qué soy yo? Soy el producto de una enorme y compleja red de relaciones causales: soy el producto de millones de años de co-evolución entre diversas especies en nichos ecológicos que ocupaban y ocupan, a su vez, nichos más amplios, y de co-evolución entre la Tierra, como sistema climático y atmosférico, y los seres que la ocupan y co-constituyen. Respi- 
ro la atmósfera que mil millones de seres están produciendo en este momento: arrecifes de coral, selvas amazónicas, fábricas de plástico. Soy el producto de cientos de miles de años de cultura humana, mi idioma es un curioso papiamento de griego y latín y árabe y lenguas ibéricas y amerindias, y éste a su vez es producto del comercio, de las guerras, de las violaciones. Soy el producto de infinitos progenitores (dos en primer grado de consanguinidad, cuatro en el siguiente, ocho, dieciséis), que llegaron aquí en diferentes momentos, de diferentes lugares, y que tienen y me dan a mí rasgos particulares; la testarudez de los Caraballo, el gusto por los juegos de palabras de los Bula. Soy un hijo del capitalismo tardío, y del imperialismo yanqui; y pienso según patrones aprendidos en mi colegio, y a través de Internet y de la televisión. Soy producto de la historia: soy Bolívar y Ghandi y Hitler y Stalin. Soy aquellas personas a quienes amo, y aquellas con quienes trabajo, y la cultura institucional de mi universidad y la ansiedad de vivir en una democracia enferma en un mundo aún más enfermo. ¿'Soy alguna otra cosa excepto esta infinidad de factores que me constituyen como un nodo en una red de relaciones, que constituye el cosmos? Buscar un yo interior o esencial removiendo la red de relaciones es como remover las capas de una cebolla buscando la cebolla interior. No soy nada excepto mis relaciones (y esto lo sabía Walt Whitman; su "Canto a Mí Mismo" es un canto al universo).

En la medida en que no comprendo las relaciones que me constituyen, en la medida en que no estoy involucrado con el mundo que me hace ser lo que soy, en esa misma medida estoy enajenado; "podemos pensar, por ejemplo, en una persona que compra una lata de Coca-Cola sin saber que lo hace porque determinada inversión en publicidad ha hecho que esta persona asocie la Coca-Cola con la prístina inocencia de la Navidad. En la medida en que mi experiencia del mundo no contiene elementos que, efectivamente, actúan sobre mí y me influyen, estoy enajenado" (Bula, 2009:12). Como indica, por ejemplo, Ulrich Herbert (1987), los alemanes, durante el dominio nazi, se enfocaban estrechamente en su vida laboral y familiar, liberándose de preocupaciones políticas.

¿Es posible la enajenación como camino? Teniendo en cuenta lo difícil que es el cambio, y lo doloroso que es el reconocimiento de aquellas amenazas e injusticias que nos vemos conminados a enfrentar, una vez las integramos a nuestro umwelt, podría pensarse que el olvidarse del mundo y concentrarse en alguna afición, o en el amor del círculo familiar, es un camino viable. En efecto, los esfuerzos por cambiar el mundo, a la luz de todo lo que en éste anda mal, a veces parecen acciones análogas a remendar las velas de un barco que se hunde en altamar. Por otro lado, contamos hoy en día con un excelente acceso a buena música, buenas películas y drogas cada vez más sofisticadas, a la vez más potentes y menos dañinas. ¿¿Por qué pues, hemos de responsabilizarnos por causas que probablemente están perdidas?

En realidad, cuando un avestruz se siente amenazada, o bien corre a una velocidad impresionante para un bípedo (hasta $70 \mathrm{~km} / \mathrm{h}$ ) o bien se de- 
fiende con poderosas patadas. La leyenda de que el avestruz oculta su cabeza proviene de Plinio el Viejo: como si al no poder ver el avestruz a su depredador, éste no la pudiera ver a ella. Esta leyenda queda fácilmente desmentida a priori por un sencillo razonamiento darviniano y un axioma igual de sencillo aunque a veces lo olvidemos: Aquello a lo que somos ciegos, o aquello que no queremos ver puede, no obstante, afectarnos. No es posible la estrategia del avestruz.

La novedad evolutiva que es el pensamiento conciente, como anota Bateson (1991), produce como consecuencia una manera de obrar y pensar lineal y teleológica. Deseamos A, para lo cual es necesario que se dé B y C y D; solemos pensar en líneas rectas, pero el mundo no está organizado en cortos circuitos lineales sino en complejas redes causales. Nos sorprendemos, pues, cuando nos vemos enfrentados con las consecuencias sistémicas de nuestros actos. No podemos creer que hayamos sido nosotros los que secamos un lago, arruinamos un río o extinguimos una especie. No puede ser nuestro sistema económico el que roba al mundo su equilibrio y a los individuos (tanto oprimidos como opresores) su dignidad. Para el pensamiento lineal que ha guiado la política exterior estadounidense (modificar el régimen político de B y C y D para obtener los resultados A), los atentados del 11 de septiembre de 2001 resultaron un baldado de agua fría, y su lección no se ha aprendido todavía. La lección consiste en pensar en redes, en totalidades: el sistema climático del mundo es una totalidad, el aleteo de una mariposa en Beijing puede causar una tormenta en Nueva York. El sistema político y social del mundo también es una totalidad, y vender armas, y apoyar regímenes y políticas corruptas por todo el planeta también puede tener efectos sobre esta ciudad. La contaminación, la proliferación de las drogas, las olas de inmigrantes y la xenofobia que las acompaña, el terrorismo, la erosión de la democracia, son todas consecuencias sistémicas de actos concebidos linealmente para lograr propósitos inmediatos e individuales, sin pensar en la totalidad en la que se llevan a cabo.

Lo que el marxismo llama contradicciones pueden concebirse como juegos de suma cero; esto es, como interacciones en las que la pérdida de un actor implica una ganancia para otro, y vice-versa. La dinámica inherentemente violenta de estas interacciones hace que también se puedan describir como juegos de suma negativa; esto es, interacciones que empobrecen a todos los actores involucrados. No obstante, dichas interacciones se llevan a cabo porque no se comprende que en ellas todos pierden.

Cuando un estado se empeña en transferir los bienes públicos a las manos de una plutocracia, es un juego de suma cero, y en último término un juego de suma negativa; el estado preso de los plutócratas, y sus instituciones, y su decencia básica, y la posibilidad de ser plenamente feliz en él, se deterioran. El enriquecimiento fruto de la contaminación; esto es, la transferencia de los costos de la contaminación a los más pobres y menos influyentes políticamente, es un juego de suma cero. Por ejemplo, una sola fábrica hace uso del agua limpia de un río, cerca del nacimiento, y deja los costos del agua contaminada a la población que vive río abajo y tiene me- 
nos dinero y poder político: gana la fabrica, pierden los demás. Ahora bien, tomando en cuenta la red causal circular de la que la fábrica hace parte, y no sólo el circuito lineal que contempla en su acción, se trata de un juego de suma negativa, en el que todos se perjudican (ver Anderson, 1996).

El cambio que viene de encontrar nuevos vínculos entre los fenómenos puede ilustrarse con la vida del seringueiro Chico Mendes, que se pasó la vida transformando juegos de suma cero en juegos de suma positiva, es decir, en interacciones que redundan en ganancia para todos los actores. Trabajando como extractor de caucho en el Amazonas, Mendes percibió que su propio bienestar y el de sus colegas estaba relacionado; por lo tanto, se dedicó a enseñarles el manejo de los números y la lectura, para que éstos pudieran exigir y negociar una paga mejor por su trabajo, de forma colectiva, convirtiendo así a sus competidores en aliados. Con el tiempo, Mendes descubrió que su trabajo en pro de los caucheros podía vincularse con el campo de la iniciativa empresarial, y formó cooperativas de caucheros que comercializaban sus propios productos sin intermediarios. Pero la forma de vida de Mendes estaba atada a la supervivencia del Amazonas; los ganaderos se apropiaban de cada vez más tierra, amenazando tanto a la selva como a los caucheros. A la sazón, muchos activistas de izquierda consideraban al ambientalismo como una preocupación burguesa y trivial; y los ambientalistas pensaban que luchaban exclusivamente por la naturaleza salvaje y ojalá inhabitada, más que por algún grupo humano. Descubrir la conexión entre el bienestar de la selva y el de los caucheros llevó a una alianza insospechada entre los activistas ambientales de Londres y San Francisco y los seringueiros del norte de Brasil, así como entre éstos, de origen mestizo, y los indígenas amazónicos, siendo estos dos grupos tradicionalmente antagónicos (ver Spinosa, Flores y Dreyfus, 109-115).

A medida que la red de conexiones se amplía y se hace más densa incluirá, de manera inevitable, al planeta Tierra considerado como superorganismo y como sistema de sustento de la vida humana. En efecto la vida humana depende del sistema de sustento de vida ecológico de la tierra (Cairns, 2007). No hay humanidad sin una proporción adecuada de oxígeno, nitrógeno y dióxido de carbono en la atmósfera, y este equilibrio no es posible sin la acción de las bacterias anaeróbicas, de la vida marina, de las plantas y, en último término, de la totalidad de los seres vivos de la tierra, operando como un superorganismo: Gaia (Lovelock, 2005).

Hasta ahora, para hablar del hombre integral, nos hemos referido a sus dimensiones cognitiva, conativa y emocional. La idea de Gaia nos recuerda que habría una cuarta dimensión, la dimensión espiritual. En efecto, Gaia nos recuerda,

en lenguaje moderno, algo que hace mucho hemos sospechado, que hemos proyectado largamente en nuestros mitos olvidados y que quizás, como arquetipo, yace durmiente en el interior de nuestro ser. Es decir, darnos cuenta que nuestro ser está aferrado al mundo y al universo, tomar conciencia de 
que no estamos aislados ni que es sólo para nosotros mismos, sino que formamos parte integral de una entidad mayor y misteriosa contra la que no es aconsejable blasfemar. (Havel, 1994)

La teoría de Gaia pone de relieve una verdad que debe afectarnos como individuos totales: existimos gracias a Gaia, somos un nodo que pertenece y es sostenido por una inmensa red de relaciones.

Una de las etimologías que se ha propuesto para la palabra "religión”, propuesta por Lactancio, es que viene de re-ligare, esto es, de reconectar, re-unir. El sentimiento de formar parte de un todo superior, el darnos cuenta de que somos uno con nuestra comunidad, con la humanidad entera, con la historia, con Gaia, nos hace participar de la grandeza de nuestra comunidad, de la humanidad, de la historia, de Gaia (ver Naess, 2001). He aquí un puente entre ciencia y teología, saber y espiritualidad: Albert Einstein, quien decía creer en el Dios de Spinoza, practicaba la ciencia con asombro religioso, maravillándose ante la "inmensidad, unidad, armonía racional, y belleza matemática del universo” (Torrance, 2002).

El juicio de Galileo puede servir como símbolo de la moderna separación entre ciencia y teología: en ese entonces, la teología pretendía ilícitamente un saber absoluto. Hoy en día, es más bien la ciencia la que peca por hybris, por arrogancia. Como ha indicado Hans Jonas, el aumento de nuestro poder debido a la tecnología debe ser acompañado por un sentimiento de humildad, de miedo ante las consecuencias imprevistas o imprevisibles de nuestro obrar tecnológico, a riesgo de destruir el legado cósmico y evolutivo que nos ha sido confiado en el presente: la humanidad y el planeta tierra (1988). Reconocer la complejidad del mundo, cultivar el asombro ante el mundo, es reconocer nuestra ignorancia (siendo infinita la complejidad del cosmos y finita nuestra capacidad de conocerlo; y siendo infinito el producto de la resta de un número finito al infinito) y la humildad a la que ésta nos conmina. He aquí una segunda etimología de "religión", proveniente de Cicerón; vendría de relegere, “tratar con cuidado”.

Para el San Agustín de Ciudad de Dios, la palabra viene de religere, recuperar algo perdido. Junto con la etimología que considera a la religión un re-leer, estamos ante la cuestión del origen. Cuando hemos alcanzado un conocimiento suficiente de la red de relaciones que es la realidad, y que nos constituye, podemos entrever en nosotros mismos, e inclusive en otros seres individuales, la totalidad de la red expresándose a través de uno u otro ente individual. Esto es, aprehendemos la red, como totalidad, a partir de un nodo particular. Esto es lo que Spinoza llama el tercer género de conocimiento (Yovel, 1990). Vistos desde el punto de vista de la totalidad, como nodos en una red, los entes individuales nos recuerdan su relación con el ser en su totalidad, “Cuanto más conocemos las cosas individuales, tanto más conocemos a Dios” (Spinoza, 1999, proposición 24 del libro quinto).

Contemplando la totalidad de las cosas se revela la conexión de las cosas individuales con el particularísimo hecho de que hay ser, de que, 
parafraseando a Leibniz y a Heidegger, es el ente, y no más bien la nada. La ampliación de la red cognitiva, conativa y emocional, puede llevar a la percepción de la conexión entre las cosas particulares y el milagro de la existencia misma. Wittgenstein, en Una conferencia sobre la ética (2005), toma como ejemplo de una experiencia ética paradigmática el maravillarse de que exista tal cosa como el mundo. En el uso ordinario de la palabra, uno se maravilla de que exista tal o cual cosa en el mundo, que determinado hecho resulte inusual en relación con otros hechos. Pero no es de esta manera, evidentemente, que nos maravillamos ante el mundo como una totalidad; Wittgenstein (admitiendo que de esta forma se estrella contra los límites del lenguaje) lo describe como el ver al mundo como un milagro. Esta experiencia ética nos conmina a ver el mundo con gratitud, a aceptarlo y a sentirnos en casa en él, sentir que pertenecemos (Bearn, 1997).

Esta aceptación no implicaría quietismo sino acción, acción que contempla el todo sistémico sobre el que actúa. Somos sistemas dinámicos y autopoiéticos que nos realizamos en el mundo; sentirnos parte de la totalidad no cohíbe esta actividad sino que la dirige. De una visión de la educación como percepción de conexiones hemos pasado a ver el desarrollo humano como un fenómeno holista y tripartito, un simultáneo e isomórfico ampliarse de la responsabilidad, el conocimiento y el involucramiento afectivo. Esta expansión se da ante un cosmos infinito, y en su desenvolverse puede entrever la perspectiva de la totalidad. Desde esta perspectiva, las cosas particulares tienen un aspecto renovado, aparecen, en palabras espinozistas, como manifestaciones del infinito poder de obrar de dios. Quisiera ahora detenerme en esta manera de ver, en el que las cosas particulares aparecen como milagrosas y así, pasar de una visión de la educación a la articulación de una manera de estar en el mundo.

El arte del género de poesía denominado jaikú consiste, en revelar lo milagroso que tienen las cosas particulares, como se puede ver en este poema de Buson:
Blanco rocío
cada púa en la zarza
tiene una gota
O también en el famoso poema de Basho:
Un viejo estanque
se zambulle una rana
ruido del agua

Si bien el lenguaje de estos poemas es objetivo, revela la manera en que el observador es profundamente impactado por el fenómeno. Ver que cada púa en la zarza tiene una gota es sorprenderse de este hecho, es maravillarse de que existan cosas como la lluvia o las gotas. El "ruido del agua" que produce una rana al zambullirse, ese ruido diminuto y único, sólo se puede escuchar debidamente en contraste con el silencio de la inmensidad, ese silencio representado en las pesadas y mohosas piedras del viejo estanque. 
Desde el punto de vista de la totalidad, la contemplación de las cosas particulares nos produce asombro, gratitud y respeto. Asombro porque las cosas individuales pertenecen al milagro de la existencia; gratitud porque nosotros también pertenecemos a este milagro, y se nos ha dado la existencia al tiempo con las cosas particulares que contemplamos. El respeto surge de la gratitud, porque reconocemos que la existencia es un regalo, algo que se nos ha dado libremente, y porque reconocemos la insondable magnitud de este regalo, condición de posibilidad para cualquier otro. Este poema de Issa manifiesta una conciencia profunda de la fragilidad de todo lo existente:

\section{Le sobrevive}

le sobrevive a todo

la frialdad

Este poema de Kito manifiesta el amor que se tiene a lo que, se entiende, viene como un regalo:

El ruiseñor

unos días no viene

otros dos veces

De la contemplación atenta y humilde de la complejidad de las cosas individuales, surge un sentimiento de respeto hacia las mismas, como se ve en este poema de Issa:

¡No la aplastes!

La mosca frota sus manos

frota sus pies

Y en este ambiguo, melancólico y profundo poema de Issekiro:

Mientras lo corto

veo que el árbol

tiene serenidad

\section{Coda}

He aquí una concepción de la educación como percepción de las conexiones ocultas entre los fenómenos, y como desarrollo y empoderamiento del individuo total. Es importante no concebir este empoderamiento como un "desarrollo de las potencialidades"; esta manera de hablar sugiere que hay un "acto" preexistente hacia el que tiende la potencialidad. Por el contrario, empoderar es hacer del educando un ser capaz de más y más diversas acciones, pensamientos y sentimientos. Mientras más se desarrolla un individuo, mayor es su capacidad de sorprendernos, y menor nuestra capacidad de control, y menor nuestro poder con relación a dicho individuo. Apostar al desarrollo pleno, al impredecible florecimiento de lo que cultivamos, implica confiar en los otros, y facilitarles un recorrido cuyo punto de llegada es desconocido e incognoscible. Esta apuesta comparte su espíritu con el poema de Khalil Gibran: 
Tus hijos no son tus hijos

son hijos e hijas de la vida

deseosa de sí misma

No vienen de ti sino a través de ti

y aunque estén contigo

no te pertenecen

Puedes darles tu amor

pero no tus pensamientos, pues

ellos tienen pensamientos propios

(...)

Tu eres el arco del cual tus hijos

como flechas vivas son lanzados

El espíritu de este poema debería permear la relación del educador con el educando, en todos los niveles y ámbitos de la educación. Debería enseñar, también, al individuo a relacionarse consigo mismo, para que se atreva a atravesar las fronteras ante las que su propio florecimiento le transporta. Y debería hablarnos algo acerca de nuestra relación con el conocimiento, algo que está encarnado en esa particular disciplina del saber que se llama filosofía.

El conocimiento, como expansión de la conciencia hacia el infinito, como indefinido vincularse con el cosmos, no puede fijarse un destino, ni, por lo tanto, un itinerario. Al deseo de abarcar la infinitud con mente, alma y corazón corresponde una disposición espontáneamente abierta e infinitamente paciente. El hogar de esta disposición es la filosofía; la paciencia y la disposición a sorprenderse son, o deberían ser, los rasgos que distinguen a la filosofía de las otras ramas del saber. Los médicos deben sanar, los ingenieros inventar y construir, los científicos sociales deben prescribir políticas o diagnosticar sociedades; y todas estas acciones están exigidas para algún momento determinado en el futuro y exigen una respuesta determinada. Sólo la filosofía tiene, o debería tener, la osadía de navegar a la deriva. Sólo la filosofía es, o debería ser, libre de premuras que no son propias de la materia de estudio sino de exigencias económicas o de otro tipo.

Hic sunt dracones, “aquí hay dragones”, decían por escrito y gráficamente los mapas antiguos a manera de advertencia o descarga de la responsabilidad, para indicar un territorio desconocido, aún no cartografiado. A tierras o mares de dragones se entraba por propia cuenta y riesgo. La filosofía, sin metas prefijadas, sin método universalizable, sin un amo o interés al servicio del cual se izan las velas, se lanza precisamente a estas aguas, y a su osadía cognitiva la debe acompañar la disposición a luchar con los dragones que se encuentre, a comprometerse moral y emocionalmente con aquello que encuentre en su exploración. La filosofía como ambición de comprender el infinito y como búsqueda a la respuesta por cómo se debe vivir son un solo y mismo emprendimiento. Y si a este emprendimiento se le ponen límites, no pertenecen a la tarea misma, sino a lo que viene desde afuera. 
Esto lo muestra sutilmente Platón al final de varios de sus diálogos. En el Protágoras, Sócrates y su interlocutor se han topado con una aporía, descubriendo que ambos sostenían posiciones contradictorias respecto a si la virtud puede enseñarse y si es o no una ciencia. En este punto Sócrates renueva su invitación a Protágoras de averiguar en conjunto lo que es la virtud. Protágoras responde: “(...) otra vez, si quieres, nos ocuparemos de eso. Ahora ya es tiempo de dedicarme a otros asuntos” (361e). En el Eutifrón, tras llegar a una aporía por definir lo pío como aquello que agrada a los dioses, Sócrates invita a su interlocutor a llevar a cabo la tarea con toda la paciencia del caso: "Por tanto, tenemos que examinar otra vez desde el principio qué es lo pío, porque yo, en lo que mi depende, no cederé hasta que lo sepa” (15c-d); a lo que Eutifrón responde, "En otra ocasión, Sócrates; ahora tengo prisa y es tiempo de marcharme" (15e); con lo que queda derribada la esperanza de Sócrates de "en adelante, [llevar] una vida mejor" (16a). La tarea de la filosofía es infinita; no podemos, por lo tanto, terminarla, si no sólo abandonarla. 


\section{Bibliografía}

Anderson, E.N. (1996), Ecologies of the Heart. Oxford University Press, New York.

Bateson, G. (1991), “Efectos del propósito consciente sobre la adaptación humana” en G. Bateson Pasos hacia una ecología de la mente. PlanetaCarlos Lohlé, Buenos Aires.

Bearn, G. (1997), Waking to Wonder. SUNY, Albany.

Beer, S. (1993), Designing Freedom. House of Anansi, Ontario

Bula, G. (2009), “Eres responsable de tu Rosa: ecocrítica, ecosofía y El Principito” en Bula, G. y Bermúdez, R., Alteridad y Pertenencia: Lectura Ecocrítica de María y La Vorágine. Unisalle, Bogotá.

Cairns, J. (2007), “Sustainable co-evolution” en International Journal of Sustainable Development and \& World Ecology 14 (2007) 103-108 Capra, F. (1996) The web of life. Anchor, Nueva York.

Damasio, A. (2003), Looking for Spinoza. William Heinnemann, Londres.

Havel, V. (1994), The need for trascendence in the postmodern world. Discurso dado el 4 de julio de 1994 en Philadelphia. Disponible en: http:/ /www.mountainman.com.au/v_havel.html

Idem (2000), Comentario durante la sesión de apertura del Forum 2000 en Praga, el 15 de Octubre. Disponible en: http://www.forum2000.cz/en/ projects/forum-2000-conferences/2000/transcripts/opening-session/ \#vaclav_havel

Herbert, U. (1987), “Good Times, Bad Times: Memories of the Third Reich” en Bessel, R. (ed), Life in the Third Reich. Oxford University Press, Oxford.

Jonas, H. (1988), El Principio de Responsabilidad. Herder, Barcelona.

Kull, K. (1998), “On semiosis, Umwelt and semiosphere” en Semiotica, vol. 120(3/4), 1998, pp. 299-310.

Lovelock, J. (2005), Homenaje a Gaia: la vida de un científico independiente. Laetoli, Pamplona.

Misrahi, R. (1998), Le corps et l'esprit dans la philosophie de Spinoza. Synthélabo, Paris.

Naess, A. (2001), Ecology, community and lifestyle. Cambridge University Press, Cambridge 
Platón (1981), Diálogos. Gredos, Madrid.

Ravven, H. (1989), “Notes on Spinoza’s Critique of Aristotle’s Ethics: From Teleology to Process Theory” en Philosophy and Theology, 4.

Idem (2003) “Spinoza's anticipation of contemporary affective neuroscience” en Consciousness and emotion vol 4, no.2 Spinoza, B. (1999) Ética (trad. V. Peña). Alianza, Madrid.

Spinosa, Florez \& Dreyfus (1997), Disclosing New Worlds: Entrepreneurship, Democratic Action and the Cultivation of Solidarity. MIT Press, Cambridge.

Torrance, T. (2002), “Einstein and God” en Center of Theological Inquiry: http://www.ctinquiry.org/publications/reflections_volume_1/torrance.htm Wittgenstein, L. (2005) Una conferencia sobre la ética. UNAM, México.

Yovel, Y. (1990), “The Third Kind of Knowledge as Alternative Salvation” en E. Curley y P.F Moreau (eds) Spinoza: Issues and Directions. E.J Brill, Leiden. 